\title{
La realización de un evento imposible ${ }^{1}$
}

\author{
Entrevista con Edgar Morin \\ Edgar Morin y Michel Wieviorka
}

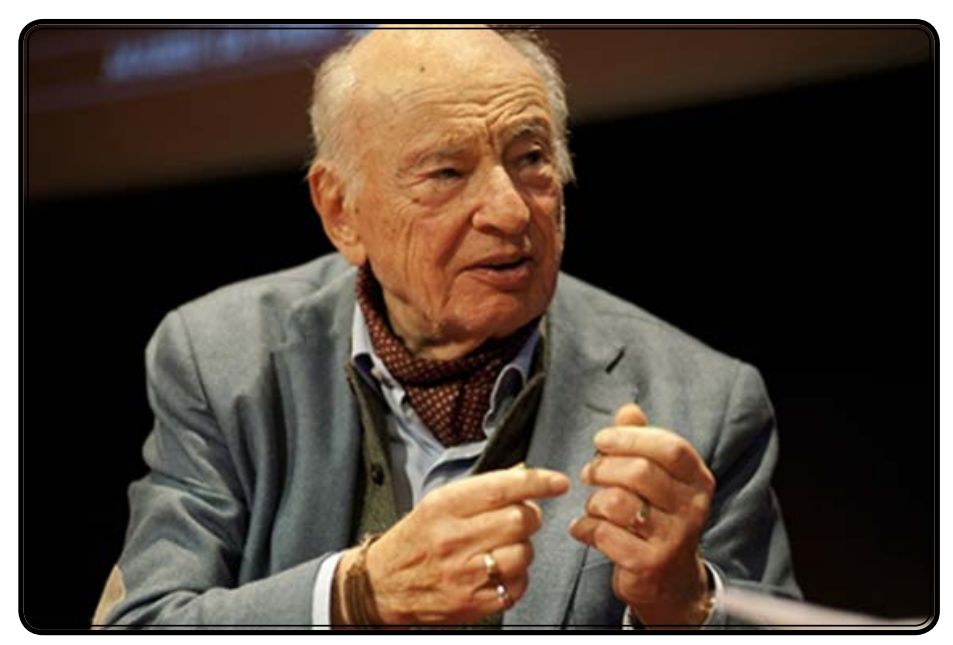

Michel Wieviorka (MW): En su momento, ¿cómo entendió Mayo del 68? ¿Que queda de

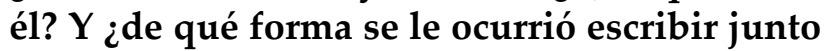
a Claude Lefort y a Cornelius Castoriadis el texto La brèche (La brecha)?

Edgar Morin (EM): Comenzaré por los antecedentes. Después de 1963 y con el conocimiento del movimiento estudiantil en Berkeley California, en 1964, me interesé en lo que denominaba la constitución de una clase de edad adolescente con autonomía propia, entre el capullo de la infancia y la integración al mundo adulto. Una clase de edad con sus uniformes, sus palabras clave, su música, sus ritos, etc.

Y en 1968, antes de mayo, me impresionó el recrudecimiento de las revueltas estudiantiles no solo en los Estados Unidos, sino también en Egipto, Polonia y los países occidentales. Di una conferencia en Milán sobre el carácter internacional de las revueltas estudiantiles: me preguntaba cómo era que, en sistemas políticos y sociales tan diferentes como la democracia popular, la dictadura egipcia o la democracia de los países occidentales, exista el mismo tipo de movimiento de protesta. El denominador común era que estas revueltas iban en contra de la autoridad sin importar el tipo de sistema.

En marzo de 1968, Henri Lefebvre, que era profesor en Nanterre, me pidió que lo reemplazara mientras hacía un viaje a China. Cuando llegué a Nanterre, vi que salían patrullas de policía, y vi a un pelirrojo inquieto que gritaba en todas las direcciones. Todavía no sabía que se trataba del amigo Dany CohnBendit. Me dirigí a cumplir con mi papel de

1 Edgar Morin et Michel Wieviorka, «La réalisation d'un événement impossible », Socio [En ligne], 10 | 2018, mis en ligne le 13 mars 2018, consulté le 19 mars 2018. URL: http://journals.openedition.org/socio/3124; DOI: 10.4000/socio.3124. La versión española es de Miguel Ángel Mahecha Bermúdez, Universidad Surcolombiana, Colombia. Agradecemos a la revista Socio y en particular al profesor Wieviorka, la autorización para traducir al español la entrevista e incluirla en el presente número de Entornos. 
profesor, a dictar el curso de Lefebvre. En este punto, un pequeño grupo de personas furiosas grita: "¡No hay clases, no hay clases! Yo les propongo una votación: "Si quieren clase, la daré; si no la quieren, no la hago." Una gran mayoría quiso clase, los pocos agitadores me señalaron de "Morin, policía", entonces cortaron la electricidad y no pude dar clase".

Estoy al tanto del movimiento del 22 de marzo y las razones que lo provocaron. Pensé que algo realmente estaba incubándose y que algo iba a suceder.

Mi joven amigo y colaborador Bernard Paillard siguió desde muy cerca los sucesos, y me informó que parte del movimiento de Nanterre había emigrado a Jussieu. A principios de mayo, fui a Jussieu, donde todos los salones estaban ocupados por grupos de estudiantes. Fui a ver a Lefort y Castoriadis y los invité para que vieran lo que estaba sucediendo -estaba comenzando el mes de mayo. Así es como nuestro trío se centró en los sucesos y gracias a la presencia constante de Bernard Paillard, seguí todo el proceso e iba con frecuencia a la Sorbona que estaba ocupada.

Publiqué una primera serie de artículos en el diario Le Monde, bajo el título de "La comunidad estudiantil". Fui el único que pudo dar cuenta de este movimiento. Ni los académicos ni los periodistas percibían alguna señal allí. Estos artículos fueron incluidos en La brèche.

Seguí los sucesos y las peripecias y hacia finales de mayo publico otra serie de artículos: «Une révolution sans visage» (Una revolución sin rostro). Lefort y Castoriadis, cada uno por su parte redactaron un texto.

Hay algunos incidentes que recordar:

- Lapassade, ebrio de felicidad, quería una banda de rock en la Sorbona, y yo, que conocía a los animadores del programa "Salut les copains", me apresuré a conseguir un artista de rock en la Sorbona.

- También conocí a Maurice Clavel en la Sorbona, quien me dijo extasiado, alzando los brazos al cielo: "¡Es la Edad Media!"

MW: Hoy, en 2018, hablar de Mayo de 1968 es evocar tiempos muy lejanos. ¿De qué naturaleza es el recuerdo más vivo que le queda? ¿es del lado imaginario, del cultural, o del lado de la subjetividad del movimiento?

EM: Lo que queda vivo es ante todo los recuerdos muy fuertes. Presencias en la Sorbona ocupada, transformada. La primera semana de mayo de 1968 fue admirable para mí. La infestación del estado hizo que todos hablaran en la calle. Los consultorios de los psicoanalistas se vaciaron de repente, todas las personas que sufrían molestias estomacales se mejoraron, y así sucesivamente. Cuando todo volvió a la normalidad, los malestares también volvieron.

Esta primera semana fue muy semejante a mi época de adolescente en junio de 1936, cuando todos se hablaban. Tengo maravillosos recuerdos de esta festiva Sorbona, la realización de un evento imposible. Recuerdos de esta guerra civil sin muerte, salvo en Flins ${ }^{3}$, de este juego serio en el que se jugó en la revolución, pero sin arriesgar las muertes a pesar de la violencia de los enfrentamientos. Entonces no queda ninguna amargura.

MW: Las relaciones con Lefort y Castoriadis fueron intelectualmente excelentes, pero ino hubo debate entre ustedes?

EM: Hubo diferencias, pero básicamente estábamos en la misma onda. A diferencia de los trotskistas, maoístas, etc., que pensaban que una revolución comenzaría, para nosotros no fue más que una brecha. Algo que iba a ser una brecha por debajo de la línea de flotación

2 Programa radial de variedades creado en 1959 y que se transmitía de lunes a viernes en el horario de $17 \mathrm{~h}$ a 19h. Era presentado por Daniel Filipacchi, Frank Ténot, Michel Poulain, Michel Brillié et Monty (NdT).

3 Manifestación de estudiantes que vinieron a apoyar a los huelguistas en la fábrica de Renault durante la cual un adolescente de 17 años murió ahogado. 
de la civilización burguesa occidental. Y no la revolución.

La única diferencia fue una palabra. Lefort quería que le dedicáramos el libro a los "enragés" ("indignados"), yo no quería, pero finalmente cedí. Cuando él pensó en los "indignados", pensaba en parte del movimiento juvenil del 22 de marzo. Los tres dijimos cosas diferentes, pero nos complementamos y sabíamos que aquello efectivamente no era el comienzo de la revolución.

MW: Al principio, fue un movimiento estudiantil, un movimiento juvenil, no fue un movimiento obrero. Solo entonces, y de mala gana, se convierte en una movilización sindical. ¿Tuvo discusiones sobre el proletariado, la clase obrera, el movimiento obrero?

EM:Demostré en mis artículos que, a diferencia de otros países, en donde el movimiento ha sido estrictamente estudiantil, se desbordó en buena parte de la juventud trabajadora juvenil y de la escuela secundaria. Sobre todo, la duración e intensidad del movimiento eventualmente involucró a los sindicatos que al comienzo estuvieron renuentes y que finalmente se precipitaron en esta brecha para arrebatarle al gobierno concesiones fundamentales. Una vez que se obtuvieron estas concesiones, se calmaron las cosas. Lo que también me llamó la atención fue el deseo de Georges Pompidou de calmar los ánimos otorgando concesiones y negociando.

Hubo desfiles impresionantes, asistí a uno de ellos rue Beaubourg con Paul Thorez, el hijo más joven de la pareja Thorez ${ }^{4}$. Este movimiento finalmente demostró el vacío de esta civilización que se creía triunfante, que creía que se estaba moviendo hacia la armonía. El Raymond Aron de la época, el que estaba equivocado, vio en la sociedad industrial la atenuación fundamental de todos los problemas principales, mientras que incluso antes de la crisis económica de 1973, el Mayo del 68 reveló una profunda crisis espiritual de la juventud.
Las aspiraciones profundas deesta adolescencia en relación con este mundo de adultos fueron: más autonomía, más libertad, más comunidad. Los trotskistas y los maoístas dijeron: "Podemos lograr estas aspiraciones. Hubo una transferencia de fe, al principio fue una rebelión, el comunismo libertario, luego el movimiento fue capturado por el trotskismo y el maoísmo con la promesa de realizar las aspiraciones juveniles por medio de la revolución.

MW: Hubo algunos momentos mágicos en 1968, pero no eran eternos.

EM: Podemos decir que el movimiento se extinguió de inmediato con la demostración a favor de De Gaulle-Malraux destruyendo repentinamente todo para ordenarlo después. ¡Pero al tiempo, no hay duda de que Mayo del 68 existió!

MW: ¿Tal vez sea porque el movimiento no fue político? Que su problema no era la política clásica, el poder estatal: el día en que la política le quita sus derechos, el movimiento termina porque la política reaparece...

EM: Sí. Pero se puede decir que la política se infiltró a través del maoísmo y el trotskismo pervirtiendo el movimiento. El final del movimiento era para mí supra e infra político. Es por eso que el movimiento del 22 de marzo y la imagen de Dany Cohn-Bendit siguen siendo símbolos muy fuertes.

Por otro lado, intencionalmente subestimé y oculté un poco toda la estupidez del movimiento, los esloganes del tipo "CRS-SS" por ejemplo. Quería considerar esto como un subproducto cuando todavía era importante.

\section{MW: ¿Y luego?}

EM: En el año académico siguiente, dediqué mi seminario de la École des Hautes Études en Sciences Sociales a las interpretaciones de las interpretaciones de Mayo de 68.

4 Maurice Thorez fue secretario general del Partido comunista francés de 1930 hasta su deceso en 1964. 
MW: Hice exactamente lo mismo que tú, ¡pero diez años después, cuando estaba en la universidad y era asistente en la Universidad Paris-Dauphine! ¡Todos los sociólogos que había se expresaron realmente, y no solo a favor del movimiento!

EM: Hay quienes dijeron: "Yo lo había previsto", ¡cuando nunca habían previsto ni dicho nada! Hubo diferentes interpretaciones que examiné a través de la reflexión. Lo que me interesaba era pensar en un segundo nivel.

En 1978, para el décimo aniversario, volví a escribir un artículo para Le Monde. En ese momento, el evento me pareció aún considerable. Por un lado, todo había cambiado, pero por el otro nada había cambiado.

Toda una serie de tendencias neoliberales se derivan de Mayo del 68. El feminismo no estuvo presente, pero surgió de allí también el movimiento homosexual. Roland Barthes era un homosexual que se avergonzaba de su condición antes de Mayo del 68, luego, se convirtió en un homosexual declarado.

Hubo cambios en los hábitos, aunque nada cambió en la sociedad. Lideré con Nicole Lapierre y algunos otros colegas, una investigación, publicada en un libro que estúpidamente se llamó La Femme majeure: nouvelle féminité, nouveau féminisme. El estudio fue interesante. Antes de Mayo del 68, la prensa femenina decía: "Prepárale una buena comida a tu marido, mantente hermosa", etc. A partir de este momento, la problematización reemplaza a la euforia. Esta prensa comienza a hablar sobre las dificultades de la vida: el envejecimiento, el marido que tiene una amante, los niños que se van. Esta problemática comenzó a ganar adeptos en muchos sectores de la sociedad.

MW: Hay dos lógicas distintas, tal vez opuestas, activadas por el Mayo de 68. En un lado está la brecha, de la que hablas. Y, por otro lado, muchos no se identifican en absoluto con lo que describes. Los activistas se vuelven clandestinos, casi terroristas, los maoístas no están lejos. El marxismo a veces doctrinario próspero, sectario, etc.

EM: Ha habido una tentación "terrorista" en algunos, pero a diferencia de Alemania e Italia, ha sido abortada en Francia o ha sido incluso mínima, quizás bajo la influencia de tutores como Sartre. Hubo más incursiones en fábricas como la de Michel Le Bris y otros, hubo cambios de vida a una rural y comunitaria, con cría de cabras. Permaneció en Larzac y en otros lugares, pero la mayoría regresó con el colapso de las esperanzas de la revolución.

En el fondo, está la victoria de un marxismo sumario que incluso triunfará en las ciencias sociales, donde todo será explicado por la lucha de clases. En 1977, este marxismo sumario se derrumba. ¿Por qué este colapso? Porque se dio al tiempo la profanación del maoísmo (grupo de los cuatro $^{5}$ ), la penetración del mensaje de disidentes en Francia, como Solzhenitsyn, que la heroica y pequeña Vietnam se convirtió en la vencedora de Camboya que procede ella misma al autogenocidio con Pol Pot. Lo mismo sucede con Cuba, que ya no se veía como un paraíso.

La desilusión, la pérdida de esperanza, ya sea china, soviética o cubana, conduce al repentino desencanto del marxismo. La clave para todo uso que hizo que todo fuera comprensible se convierte en una molesta tontería. Este es un fenómeno del que me he beneficiado: mi primer volumen de La Méthode (El Método) sale en 1977, en medio de la crisis del marxismo y el declive del estructuralismo, y despierta cierto interés debido únicamente a la situación económica. La ideología que se superpuso en Mayo del 68 se disuelve aún más, mientras tanto, viene la crisis económica de 1973, que alteró en gran medida las condiciones por las cuales los jóvenes podían irse silenciosamente, regresar y encontrar trabajo etc.

5 Es así como se les llamó a los cuatro líderes chinos cuya adhesión al poder fue consecutiva a la Revolución Cultural y cuya caída en 1976 representó la del maoísmo radical. 
Pero el Evento del 68 sigue siendo para mí muy importante. En el aniversario de 1988, comienza sin embargo a desvanecerse. Sus héroes simbólicos han evolucionado.

Iba a olvidar un punto importante: entre las interpretaciones de Mayo de 1968, vino la de Régis Debray, mucho más fuerte porque estaba en prisión en Bolivia en ese momento. El dice que "el 68 de mayo es más el triunfo de la sociedad de consumo que su desafío". La verdad es que, de hecho, muchos líderes de estas organizaciones revolucionarias que han perdido toda esperanza han logrado una conversión total. Benny Lévy, por ejemplo, se apresuró a leer el Talmud.

MW: Pero Benny Lévy ¡no es la sociedad de consumo!

EM: ¡Es verdad! ¡Encontró otra fe! Libération evolucionó. Todos han cambiado. Él no permaneció como un guardián del Templo. Lo que quiero decir es que la pérdida de la fe revolucionaria ha llevado a transformaciones y aceptación totales de la sociedad tal como es. Muchos se encontraron insertados en el mundo de la intelligentsia. Incluso muchos trotskistas se han vuelto burgueses.

MW: La imagen que usted propone, finalmente, es la de un movimiento que tuvo una corta prehistoria, Berkeley. Llegó el 68, el soplo del momento fundante que todavía se encontró en 1978, y luego todo lo que se va o aparece en otra parte.

EM: Hubo luego huelgas importantes como en 1995, revueltas estudiantiles, especialmente contra la ley Devaquet. Pero ninguna tuvo el carácter simbólico y mitológico de Mayo del 1968. Existe una tradición de revueltas estudiantiles, pero nunca nada comparable a la del 68.

El evento para mí se redujo en 1988, fue el final del comunismo, la guerra fría terminó. El Mayo del 68 francés aparece para mí como un momento simbólico de crisis de la civilización, donde surgieron aspiraciones profundas, casi antropológicas (más autónomas, más comunitarias) y renacieron en otras formas.
Sigo diciendo que muchas cosas han cambiado sin que nada haya cambiado. Especialmente en el nivel de modales, sentimientos, ideas. Y recuerdo que la clase adolescente ya se había formado antes de Mayo del 68 favoreciendo su ímpetu.

MW: Al escucharlo, el aliento se mantiene hasta 1977-1978, y hoy, Mayo del 68 abandona la memoria, abandona lo imaginario, el lado mítico y se convierte en historia.

EM: Y con la continuación de una controversia sorda. Entre los que siguen pensando que Mayo del 68 no tuvo nada de revolucionario y permitió la adaptación a nuestra sociedad, y aquellos que piensan que Mayo del 68 tuvo una importancia liberadora en las costumbres, entre los que me cuento. Mis artículos sobre el momento no fueron comprendidos por personas como Henri Weber, quien habló de "ensayo de vestuario". Diez años después, me dijo: "Tenías razón", lo mismo para Dany Cohn-Bendit.

Dany es el tipo que, aunque evolucionó en sus ideas, permaneció característicamente igual. Esta es la verdadera encarnación de Mayo del 1968, no los trotskistas u otros. Fue un genio estratégico extraordinario e inspirado.

MW: Es 2018, estamos en la conmemoración de los cincuenta años, con toneladas de publicaciones sobre Mayo del 68. ¿Deberíamos conmemorar? ¿Hay que hablar de Mayo del 68 como un momento puramente histórico? ¿No deberíamos darle sentido a esta llama?

EM: Sesenta y ocho personificó las aspiraciones más profundas que fueron principalmente traídas por la juventud estudiantil. Aspiraciones que los jóvenes sienten y que olvidan cuando son domesticados por la vida que los integra en el mundo. Aspiraciones a más libertad, autonomía y fraternidad, comunidad.

Totalmente libertario, pero siempre con la omnipresente idea fraterna. Combinaron esta doble aspiración antropológica que surgió en diferentes momentos de la historia de la humanidad. Creo que el significado histórico de 
mayo de 1968 es grandioso porque reveló esta aspiración; y hemos visto cuán fácilmente esta aspiración fue domesticada.

Eso es lo que sucedió con el comunismo también. El Mayo del 68 trata de una renovación de esta aspiración humana que regresa de vez en cuando y que volverá de nuevo en otras formas.

MW: En los años posteriores al 68, el debate es extraño, los estructuralistas ocupan la parte superior de la acera en la vida intelectual, a lo sumo lejos de la idea de actor o sujeto. Sesenta y ocho a menudo ha sido interpretados en categorías estructuralistas, marxistas o de otro tipo. ¿Cómo experimentó usted el dominio de las interpretaciones inspiradas en Althusser, Lacan, Bourdieu, esas visiones de 68 que están tan lejos de lo que propone?

EM: Bourdieu no se manifestó en absoluto en Mayo de 1968, mantuvo una prudencia de serpiente hasta 1995, cuando de repente fue un líder de la clase trabajadora. Mayo del 68 significa el comienzo del declive del estructuralismo, que triunfó especialmente antes, con el lacanismo, el althusserismo.

El marxismo althusseriano es una forma de esclerosar el marxismo devolviéndole el valor de la verdad absoluta. Terminará por colapsarse en 1977. El mensaje estructuralista se agota gradualmente en la década de 1970. El estructuralismo nunca ha dominado las mentes que fueron, en mayo de 68, líderes y seguidores. Yo mismo, al igual que Lefort y Castoriadis, me convertí en metaglobalista, porque estaba el informe Jruschov, la revolución húngara y su represión, la toma del poder por De Gaulle. Comenzamos a evolucionar a partir de los años 1958-1960. En esos mismos años, es el althusserismo que se impone en la crisis del pensamiento. Althusser dijo: el marxismo es ciencia, de ninguna manera es filosofía. Lacan dijo: la biología no tiene nada que ver con Freud. Además, establece la separación entre lo simbólico y lo imaginario como si fueran dos mundos cerrados. Incluso el gran Lévi-Strauss tiene categorías que limitan el conocimiento.
Todos estos pensadores, que, además, tienen genio, eliminan la historia, el tema, la complejidad. Éramos un grupo muy pequeño tratando de salvar todo eso.

\section{MW: La paradoja es que, hasta aproximadamente 1977, los actores, investigadores $y$ sociólogos se refieren masivamente al pensamiento estructuralista $y$ al marxismo.}

EM: Sí, buscaban la seguridad y la certeza de la cientificidad, especialmente en el campo de la sociología. El genio de Bourdieu ha sido decir: yo soy el científico, yo soy la ciencia, el resto es literatura o chisme. En 1963, con su libro Les Héritiers, piensa demostrar científicamente que aquellos que tienen éxito en la escuela son hijos de las clases cultivadas, que tienen un legado cultural. Mientras que, al mismo tiempo, las encuestas adelantadas por Noëlle Bisseret (1974) y Mohamed Cherkaoui muestran que el éxito no viene de la capital "cultural" que han heredado sino del capital monetario de los padres y también de la atmósfera colectiva de las clases.

La tesis de Bourdieu, científicamente, es totalmente falsa, pero fue ella quien triunfó entonces como verdaderamente científica. Esto es parte de las grandes imposturas francesas. Era el mismo caso de Sartre: cuando él era más ciego en política, jera el momento en que parecía más lúcido!

Por ese entonces, Touraine redescubre el sujeto. Él era el único que tenía la sensación de movimiento, Bourdieu estaba del lado de la rigidez repetitiva.

\section{MW: ¿Era allegado a Touraine, hablaba con} él a menudo?

EM: Fuimos reclutados juntos en el Centro de Estudios Sociológicos en 1961 por Georges Friedmann, cada uno trabajaba en sus intereses, pero éramos amigos. Siempre he tenido estima por él, podía parecer duro y rígido, mientras que, sobre todo, tenía un verdadero rigor mental y no hizo concesiones. Creo que a él también me caía bien. En mayo de 1968 estábamos en el mismo lado de la barricada. 
MW: La imagen que tengo de usted es que, una vez pasó Mayo del 68, en lugar de quedarse en Francia y participar en la vida sociológica francesa a riesgo de ser marginado, toma la decisión de alejarse, viaja a Italia y a los Estados Unidos y, sobre todo, descifra nuevos paisajes. Mientras que Touraine permaneció mucho más presente, emancipado en el debate francofrancés y creo que ha perdió mucho tiempo y energía.

EM: Desde los años 1962-1963, con Lefort y Castoriadis participamos en CRESP y nos convertimos en metamarxistas, reflexionamos sobre el pensamiento. En los años 1965-1966, formé parte del grupo de los diez fundado por el Dr. Jacques Robin con cibernéticos, biólogos, etc. Fueron mis inicios en la cibernética.

Mi oportunidad fue en 1969 al ser invitado al Salk Institute en California, que estaba en su último año del apogeo de la cultura juvenil. Fue como un permanente mayo de 68. Me sumergí con euforia en este universo.

Al mismo tiempo, me inicio en la teoría de sistemas, leo a Von Foerster. Continúo en California mi reorganización conceptual, iniciada en París. Volviendo de California, con Jacques Monod, que era un viejo amigo, tenemos la idea de formar el Instituto Royaumont de Bioantropología. Queríamos vincular el lado biológico y el lado antropológico.

Una vez inmerso en él, me fui a escribir La Méthode (Morin, 1977-2006) para tratar de repensar nuestro conocimiento y revisar las estructuras del pensamiento. Era una ambición difícil de comprender, estaba estancado en París. Para escribir La Méthode tuve que abandonar París, incluso Francia, durante no poco tiempo.

MW: ¿Usted conocía a Paul Ricoeur, especialmente en el momento de su asalto, en enero de 1970?

EM: Yo conocía al grupo de Esprit, entonces sí, lo conocí. Me conmovió este pobre hombre después de su agresión, es alguien a quien aprecié mucho. Y eso sostengo para uno de los filósofos franceses más importantes. Colocó en el centro de su pensamiento la idea de la hermenéutica: no se puede escapar de la interpretación, esa es una idea capital para mí.

\section{Referencias bibliográficas}

Bisseret, Noëlle, 1974, Les inégaux ou la sélection universitaire, Paris, Presses universitaires de France.

Groupe de diagnostic sociologique (Nicole Benoît, Edgar Morin, Bernard Paillard), 1972, La Femme majeure: nouvelle féminité, nouveau féminisme, Paris, Club de l'Obs et Seuil.

Morin, Edgar, Lefort, Claude et Castoriadis, Cornelius (sous le pseudonyme JeanMarc Coudray), 1968, Mai 1968, la brèche: premières réflexions sur les événements, Paris, Fayard.

Morin, Edgar, 1977-2006, La méthode, Paris, Seuil, 6 vol. 


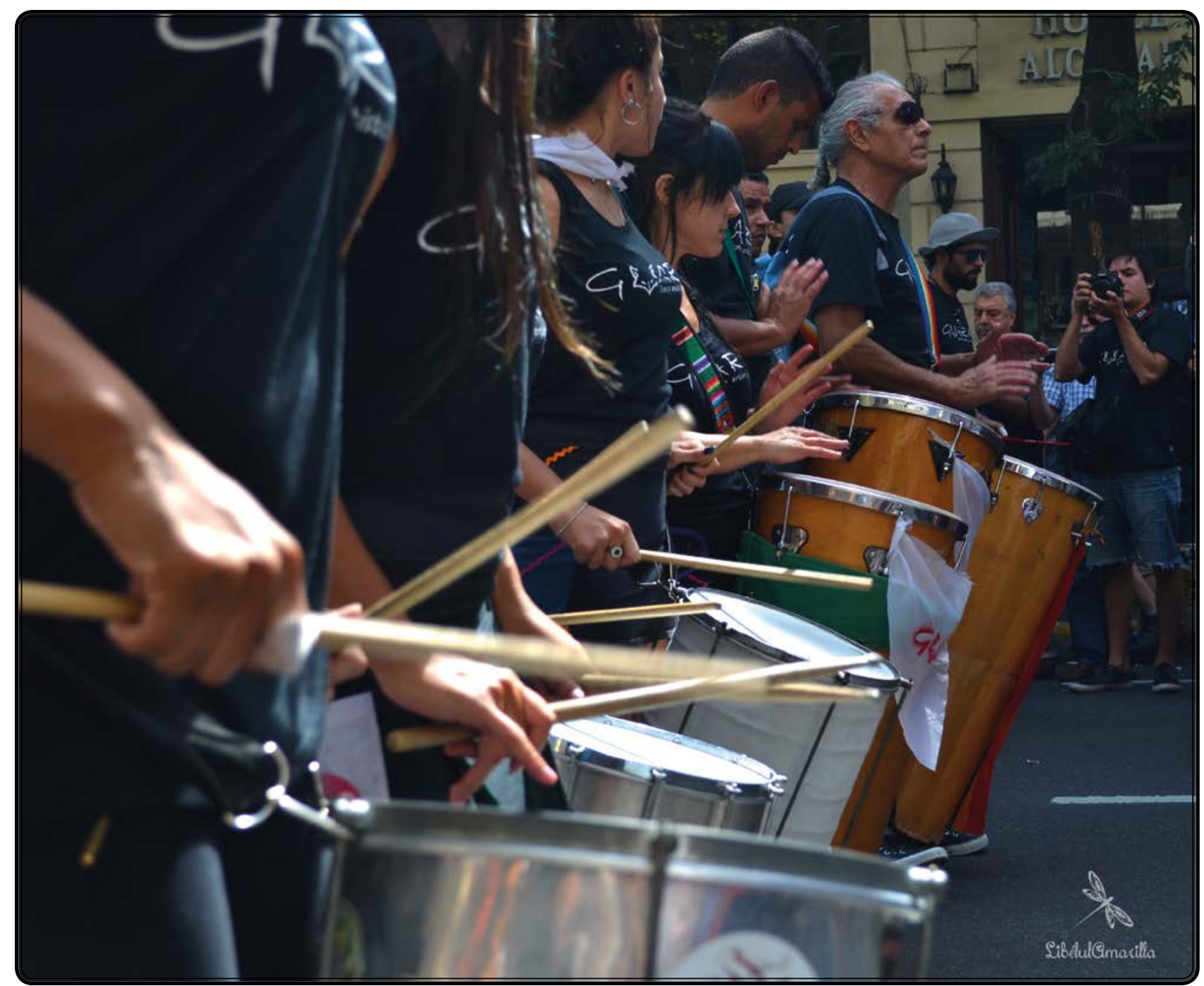

La sangre a máxima velocidad. 